the size of the thyroid gland; $(c)$, to remove the plastic new formations behind the eyeballs.

The Treatment, therefore, would be:

1. Galvanism to the sympathicus, vagus and pneumogastric, in such form as to reduce the pulse and stimulate the heart's action. In other diseases, galvanism quiets to such a degree that patients fall asleep while the application is given.

The Strength of the Current must be regulated according to the toleration of the patient in every case. The operator must exercise great care in slowly increasing the electro-motive force of the current, till the exact amperage is found, and every step of increase and decrease must be made with care and without any accidental shake or jerks of the current. The exact measure in milliamperes can not be advised and depends entirely on the sensation in each individual case. Some patients may be so irritable that even 2 milliamperes may be too much, while others can endure 20 or even 30 . It is also essential to regulate the strength of the current in the same patient according to the region to be galvanized, to the size of the electrodes and the resistance between the two poles.

The Statir Electricity will assist to regulate the vascular circulation, allay nervous irritation, creating a sedative to the heart and a more refreshing sleep.

2. The thyroid gland will be reduced with almost a certainty by the negative pole of the galvanic battery. Some report good results by applying both poles near the gland, one on each side. While this may have result the method is harsh and not rational. Surgical means have not been successful.

3. The protrusion of the eyeballs can only be cured by diminishing the new formations of tissues, grown behind the eyeballs, by which the eyes have been pushed forward. This can be done by the use of the negative pole to the eyes, which acts like an electrolysis absorbing the foreign tissues. The complications have to be treated according to indications.

The static electricity is here recommended ouly as an assistant and must be given with care. Sparks are contra-indicated, as they are too severe and will create of ten more nervousness and even pain. Breeze or spray will act well, allaying pain and regulating the circulation.

There Should be Avoided: Too strong currents, too long séances, which tire the patient and over-stimulate internal electrolysis, and surgical electricity. The faradic current has been used and recommended, given with certain precautions, but it seems it is contra-indicated, as a severe measure, which overstimulates and disturbs more the diseased nerves.

With regard to general rules, avoid also excitement, over-exertion, stimulants, strong tea and coffee. It is evident that the treatment, and especially the application of the electricity, must be intrusted to an expert, and that the family battery for self-use (or abuse) is entirely out of the question.

14 West 36 th Street.

BIBLIOGRAPHY

G. Martin: Exophthalmos pulsatile de l'orbite guiri par l'electro puncture. Jour. de Méd. de Bordeaux 1880-41, x, 546,559, 571, 581 .

Bartholow: Electro Therapeutics, p. 192.

Blackwood, H. B. D.: The Treatment of Exophthalmic cioitre by Elec tricity. Phila. Med. Times, 1880-81. xi, 448-452.

Chyostek F.: Beitrigge zur Electrotherepie, Morbus Basedowi Wien Med. Presse, 1869, x, 133, 484, 505, 557, 583, 653, 919, 950, 1086.-1871, x ii 1032, 1054, 1101, 1131, 1155, 1300, 1332. 18:2, xiii, 497, 598, 729, 889, 942, 985, 1012 , 1036, 1052 . 1875, x vi, $857,883,907,957$.

A. Erienmeyer, jure: Functionstoerungen des Sympathicus und Yagus: Morb. Basedowi, dec s.g. Galvanizacion des Sympathicus. Cor Bl. Y. deutsch Gesellsch $\mathrm{f}$. Psysiet, etc. Neuceid, 1877 , xxifi, 113-127, 1 pl. schen Krankheit, Verhd. d. Berl. Medic-(iesellsch. (1871-73.) 1874, iv.pt 116-121.

T. W. Poole: Electricity as a Paralyzing Agent in the Treatment of ophthalmic Goitre. Med. Rec. N. Y., 1880 , xviii, 569.

A. D. Rockwell: On the Value of the Galvanic Current in Exophthal. mic Goitre, as illustrated in the treatment of four cases, Med. Rec. N. Y 79 xvi, $317-319$

A. Rockwell: The Iilectrical Treatment of lixophthalmic Goitr. Trans. Am Med. Assoc. Phil., 1880, xx xi, 177618:3. Also Med. Rec. N. Y. vivili. $284-280$. Vizioli: Electroterapie Practica. Morgagni, Gennajo, 187s, 1. 69.
ziemssen's Cyeloprodie, vol. xiv.

\section{ELECTRICITY IN THE TREATMENT OF OCULAR NEURALGIAS.}

Read in the Section on Neurology and Medical Jurisprudence. at the Forty-sixth Annual Meeting of the American Medical BY HORACE M. STARKEY, M.I. CHJCAGO.

It is with much diffidence that the writer responds to the invitation of your chairman to present a paper to this Section; for if there is any class of men for whom he has the most profound respect and before whom he is inclined to stand in silent awe it is those who are solving the complex problems presented in the study of the construction, functions and diseases of the nervous system. $\mathrm{He}$ is, however, the more willing to present a very simple and practical fragment to this symposium, because he is not aware that much has been written on this particular phase of the subject, and because he finds no reference to it in the very able paper on "Electro-Therapeutics of Diseases of the Eye," read before the last meeting of the American Electro-Therapeutic Association, by Dr. L. A. W. Alleman, of Brooklyn.

The intimate relation between eye-strain and disease of the nervous system is so well known as not to require mention. Many persons with weak and unstable nervous system are kept for years in a condition of invalidism, and suffering because of a constant excess of expenditure of nervous energy in some particular direction. Probably the most frequent source of such excess of expenditure is to be found in the eye and its appendages. It is the duty of the ophthalmologist to seek out and endeavor to correct these various sources of irritation, whether due to faulty shape of the eyeball, to irregular action of the eye muscles, to defective nerve impulses or to inflammatory diseases. Many patients are found in whom an error of refraction, or difficulty in maintaining the eyes in position for single binocular vision, or weakness of the external and internal muscles of the eye, or all these combined, have been for years the cause and source of headaches and pains in and abont the eyes. Most of these cases are relieved with more or less promptuess by removing the cause. A certain number of them, however, are not so relieved. The long-continued over-stimulation and irritation of the nerves seem to have induced a hypersensitive condition and a habit, as it were, so that, after the most careful correction of refraction and of muscular balance the neuralgia continues.

Many of these persons just described, whose condition is truly pitiable, appear to be relieved by the systematic and careful use of electricity. But while many are so relieved, some unfortunately are not, and continue to have almost constant pain, more severe on use of the eyes, notwithstanding all that we can do for them. As we are more careful and exact in diagnosis, however, the number of such unrelieved cases becomes smaller.

There are two classes of the patients mentioned above, to whom electricity may be advantageously 
applied: 1 , those with weak extrinsic muscles who may receive the primary faradic current for its direct effect upon those muscles; and 2, those in whom neuralgia persists after removal of the exciting cause, and who should receive the galvanic or the secondary faradic current.

A brief description of the method of application may be serviceable. First, as to time. The time required for a treatment is from two to eight minutes, with a probable average of four or five minutes, depending upon individual peculiarities. We probably all begin any electrical treatment with a minimum of time and current, and then increase both as we find indications for so doing. The indifferent electrode of absorbent cotton, three inches in diameter, is held by the patient to the mastoid, and neck just below the mastoid on one side the first half of the application, and on the other side the last half. In applying the faradic current a double-eye electrode may be used over the eyes, but the operator's hand makes altogether the best electrode, because the fingers can be used to single out the different muscles and convey the current more directly to them. The current employed should be mild, so as to produce a sense of tingling with little or no actual pain. Unfortunately we have as yet no practical means of measuring the faradic current. For the persistent neuralgias the secondary faradic current should, from theoretical grounds, be most useful, but practically, the weakest application of this current about the eyelids is often so painful that it will not be tolerated. The sinusoidal current would probably be better borne. Very decided and immediate relief is frequently obtained from the yalvanic current with the anode as the active pole. In this application, the time and the position of the indifferent electrode are as stated above, while the active positive electrode, which is preferably double, is applied by a gentle massage motion to the lids, cheeks, brows and temples. The amount of current required is but from 2 to 5 milliampères, though in some cases even this very small current is too great for comfortable use. The current is usually very soothing and grateful, and patients frequently express surprise at the rapidity with which the pain is relieved and at the calm content and drowsiness that steals over them. This effect is very likely due in part to the action of the current on the cervical sympathetic. The duration of relief from pain is quite variable; it may at first be but a few minutes and it may continue for several hours. Usually, where benefit is to be secured, the time of relief increases as the treatment progresses, so that in a case where the first application gave relief for one hour, the third may give relief for two hours, and so on, until the pain is absent from one day to another, when the time between treatments may be lengthened and ultimately the pain is entirely relieved. A few cases were briefly summarized, but the limit of papers in this symposium will not permit their introduction.

Notf.-A time limit of iour minutes was placed upon these papers.

IOSCUSSION ON PAPERS READ BY DRS. WATSON, MASSEY, NEWMAN, AND STABKEY.

Dr. William J. Herdman, of Ann Arbor, Mich.-I was sorry that Dr. Watson did not more specifically state the nature of the esophageal strictures with which he had been dealing. His experience has certainly been very satisfactory. The procedure he adopted is that which I have generally found, from examining the literature of the subject, to be most likely to result satisfactorily, that is, the gradual dilatation of the stricture with the assistance of the negative electrolytic action. What $I$ believe to be the fact as demonstrated by laboratory tests on living tissues with negative electrolysis, is that by a cataphoresis we have drawn to the spot, when the negative pole comes in contact with the issue, an increased fluidity. Not only is the Huidity increased, but at the same time we hare an alkalinity produced by negative electrolysis. You have there the conditions for gradual disintegration of flbrous tissue. Where you have a purely spasmodic stricture, as possibly was the case in some of the instances mentioned this morning, it is overcome by action through the nervous system. By passing the currerit from above downward and producing the natural order of esophageal contraction, you habituate that part of the esophagus to pursue the normal peristaltic action. Peristalsis in the esophagus is reversed in a good many of these cases and much of the difficulty arises from some part contracting below while the upper part is dilating; in other words an irregular distribution of nerve impulse to the muscular tissue occurs, and you can gradually overcome that by the electric current. It matters not in that case whether it is the positive or negative pole. But when you have fibrous tissue to deal with, you have a pathologic varrier which is not spasmodic, but genuine and real to overcome, and there electrolytic action by means of a negative pole is essential. To my mind it is the only rational procednre we have. A surgical procedure leaves only another cicatricial band. By the cataphoric action of the electricity you increase the fluidity of the part and this fluidity distends the fibers in the cicatrix; then, by means of the alkalies which are drawn there by electrolytic action the tissues are dissolved. You are practically using an alkalin caustic. This is the same process that Dr. Newman has adopted for the removal of cicatricial bands in the urethra. It will serve the same purpose for the ophthalmologist who attempts to dilate a stricture of the nasal duct, and it will dissolve cicatricial bands in the neck of the uterus. I have used this method over and over again in esophageal stricture and frequently in urethral stricture. It is a physical process which can be demonstrated at any time upon living tissue in the lower animals.

There is one thing that was said by the author of that paper which causes me to doubt the efficacy of his method. He makes use of aluminum electrodes. Now aluminum is the only metal which is dissolved by the alkalies or by use as the negative pole, and his electrode is not only dissolved away in this manner, but there is a question as to whether he does not get an irritating effect from the sodium aluminate and the potassium aluminate which is formed at the point. That these substances are formed at the negative electrode during electrolytic action when aluminum is the material employed, I am quite satisfied from tests. I have had made for me some sodium and potassium aluminate in the pure state, with the view of testing its action on the tissues. It is very acrid to the taste, but $I$ have not as yet investigated its action on living tissue to determine to what extent it is irritating. There is no question that certain substances are carried into the body by means of the negative electrode. There are those who hold that cataphoresis is carried on solely at the positive pole, but there is a cathodal diffusion as well. It is just as well to make use of steel electrodes as those of aluminum. Dr. Newman has taken up the interesting and perplexing subject of exophthalmic goitre. This one fact has come out from all recent methods of treatment advised for exophthalmic goitre, that galvanism is an indispensable element in the treatment. I have had occasion to look over the literature of exophthalmic goitre during the past eight or ten years pretty thoroughly, and during that period $\mathrm{I}$ do not think there is an author speaking of it or a writer writing concerning it, who does not put galvanism in a prominent place in the method of treatment; but it is amusing to see what a variety of methods they have employed for applying galvanism. Some make use of the negative pole over the thyroid, some the positive. Some treat the cervical sympathetic, putting one electrode underneath the ear and the other on the sternum. with a view to bring as much of the cervical sympathetic under the influence of the current as possible. Others adopt a transverse method. There is very little that can be inferred from this, as to what value or what particular effect it is that galvanism produces in this treatment. Every one has this idea as to the pathology of exophthalmic goitre, and I have had mine for a good many years. The notion of the pathology differs almost as much as the persons speaking of it, each one seeming to have a different conception. This only indicates to us how little we know about it as yet. I have now had twenty-three cases of exophthalmic goitre; 
-every one of these, although some of them seemed to be desperate at the outstart, are well to-day. The worst case I can recollect is that of a woman in Kansas who was bedridden and very extensively edematous. Her respirations were 40 to 45 per second and her pulse rate was 140 . She was unable to bear a teaspoonful of any nourishment on her stomach, That woman is perfectly well. Others have not been so serious in their conditions, but some of them were certainly very low. Galvanism was in all of these a very prominent part of the treatment. I would not regard galvanism of itself as the only method to be employed; in fact, I regard it as absolutely essential to make use of accessory measures, such as cardiac stimulants and measures for promoting nutrition. My experience may not be different from others, because I think other measures of treatment of this malady are more successful than those of a few decades ago. I am presumptuous enough to regard this disease as always curable.

As to static electricity in exophthalmic goitre, I think its effects are good. It acts as a vasomotor stimulant and assists in that way. I was extremely interested in the paper read by Dr. Kellogg upon the physiologic effects of the sinusoidal current. In the treatment of that subject, Dr. Kellogg has made considerable progress toward accuracy in the use of electricity. D'Arsonville, some few years ago, made the statement that the physiologic action of electricity depended upon the "curve of excitation" produced by the instrument employed. We have in static electricity an alternating current of extreme rapidity. Billions of alternations take place in the course of a second during the passage of the spark. The current, however, is very minute in quantity. The electro-motive force of the current is enormous it is sometimes millions of volts. The amourt of electromotive force required to cross six or seven inches of dry air would need to be enormous. The effect produced physiologically by such an electro-motive force, with a very small current, but a current which is rapidly alternating, must differ much from that of an induction coil which is alternating perhaps only two or three hundred times in a second, where the electro-motive force does not exceed 30 volts and where the current as compared with the static machine is greatly in excess. The static machine may have only .1 of a milliampere of current, where the induction coil may have 10 milliamperes or more. All forms of electric apparatus differ in the character of the curve which is produced. D'Arsonville called that the "characteristic of excitation," and the "characteristic of excitation" has its relationship to physiologic action. Dr. Kellogg brought out this fact in regard to the action of the sinusoidal current. This, he says, has extreme penetrating power, so that its action upon the muscular system is very decided; in other words, that it does not act upon the sensory nerves to any extent, but it does act markedly upon the muscular tissues, and for that reason serves a great variety of purposes that no other current serves so well. I think the reason for this lies in its peculiar "characteristic of excitation." In other words, that the sensory nerve terminals do not respond to an alternation of that character while muscular tissue does. It is not probably due so much to the penetrating power, as to the char acter of response which a sensory nerve is capable of making. He finds, for instance, that this current will produce no sensation at the temple, whereas there will be sensations of light excited in the optic nerve or in the retina. Now we know there is a great deal of difference in sensitiveness between the retina and the skin, and the reason it excites the retina when it does not in any way cause sensation on the skin is not, in my opinion, due to the penetrating powers but to the fact that the nerve distribution in the skin differs in the manner in which it responds to external excitations from that which we find in the retina. The retina is capable of responding to light, which, as we all know, has billions of vibrations per second. I believe that in our investigations concerning electric action we will eventually have for one purpose one form of current, and for another purpose a different form, according as the tissues respond to one or the other. We all know that we can get such a rapid vibration and high voltage of current that it can be passed through the system without our knowing anything about it. In the atmosphere of Tesla's laboratory you have vibrations passing through you and at such voltage which, if slower and lower, would kill instantly, but being so rapid they have no appreciable influence on the economy. In our therapeutic applications of these various forms of electricity, we must eventually know what is the "characteristic of excitation" of every machine we make use of, and in that way we will get a scientific application of electricity that will have its physiologic and therapeutic counterpart, and I think toward that result we are rapidly tending.

Dr. G. Betron Massey, of Philadelphia-One point in Dr. Herdman's remarks I might take exception to, in regard to the excitation of the sense of vision by the sinusoidal cur rent. Heretofore the sense of vision has been excited only by the galvanic current and not by the faradic. It has occurred to me that the reason why the sinusoidal current causes a response by the retina is on account of its larger amperage. I can not say what the amperage of this machine is ; it is somewhat difficult to find out as it is an alternating current. It is well known that it is not a direct excitation that necessarily causes the sense of light, but a reflex one. That was a matter under considerable discussion some years ago, and I myself, in 1885 , contributed to the American Neurological Association the report of a case of anesthesia in which the absence of the galvanic test was marked in an area of anesthesia about the size of a dollar over one eye; no matter how strong the galvanic current we could localize in that point, although witbin an inch and a half of the retina itself. Yet, anywhere outside of that area, galvanic currents with interruptions would produce both taste and sight. One of the uses of the sinusoidal current will be the power of giving rapid alternations of practically slight galvanic currents of such regularity and gradation as to cause muscular contraction without pain, since the variation is not quite acute enough or irregular enough to cause sensation.

Dr. Hugh T. P.trick, of Chicago-I would like to differ with Dr. Herdman when he says the galvanic current is an indispensable means of treatment in Graves' disease. I would like to make the point that in many different varieties of treatment of this disease, it improves and pursues a favorable course, although not generally to complete recovery. I happen to have seen in the last three or four years, about sixty cases of Graves' disease. These were seen under the care of various observers and were consequently under various methods of treatment; some of them purely hydrotherapeutic, some purely faradic, some purely galvanic, some purely dietetic, some purely rest treatment, and so on. I do not think that among all these cases I saw one which was treated for a length of time, sufficient to judge of the treatment, that did not improve. The only thing which I saw in common in the treatment was repose, rest and general hygienic measures. Now I beg leave to offer the opinion that the rest treatment and general treatment alone may give exceedingly favorable results in the treatment of this affection, equal to any that have been produced by the galvanic current; and I do not think that our enthusiasm for electrical treatment should carry us so far as to say that galvanism indispensable in the treatment of Graves' disease.

Dr. George J. Preston, of Baltimore-One little point concerning exophthalmic goitre, and that is the immense loss of electrical resistance. That was called to my attention some ten years ago by Vigarow, who was, I think, the first observer of the phenomenon, that in cases of this disease there was practically no electrical resistance. In the somewhat limited experience I have had in such cases, I have been able to confirm this, that the electrical resistance is practically nil. I have been quite at a loss for any satisfactory explanation of this point. I asked my friend, William J. Morton of New York, an authority on such matters, and he said that he thought it was due largely to excessive moisture of the skin. My own experience would not bear that out. There is evidently some speciai susceptibility to the negative current in these cases. It is a noteworthy fact that when the thyroid has been removed, surgically, the same loss of electrical resistance results, and this brings out a curious similarity between the removal of the thyroid surgically and exophthalmic goitre, which seems to bear some remote relation to the thyroid gland.

Dr. G. B. MASSEY-Can the Doctor tell us what the resistance was in these cases? It is startling to hear that there is no resistance; even a copper wire has resistance.

Dr. Preston-I did not expect to be taken literally when I said that the resistance was lost. I frequently measured the resistance and found it down as low as about $500 \mathrm{ohm}$ and in one case as low as $300 \mathrm{ohms}$, using an electrode about $4 \mathrm{~cm}$. in diameter. I used an electro-motive force of perhaps 20 to 30 milliampères. I used an ordinary Wait \& Bartlett machine. Normal cases under like conditions would give a resistance of about $2,000 \mathrm{ohms}$.

Dr. Cras. G. Hrur, of Baltimore-Speaking generally of electro-therapy, I wish to say that we have much to learn in that line, notwithstanding the rapid advancement recently made, as evidenced by the excellent scientific papers read before this Section. I recall many cases of the application of electricity for the reduction of the thyroid in exophloaded From: http://jama.jamanetwork.com/ by a Oakland University User on $05 / 31 / 2015$ 
thalmic goitre, and some cases would melt away like magic while in others there was practically no effect. I have applied electricity in other lines, in surgery for instance, and sometimes with very good results. I recall one case of a small fibroid beneath the skin which would have caused no inconvenience except for the pressure upon it of the dress sleeve. The patient, a nervous woman, objected to the knife. I applied the constant current, not expecting much from it, and was very much surprised in two or three applications to find that the tumor disappeared entirely. There is another point which was not brought out to-day, and that is one of the peculiar effects of the electrical current in the production of ozone in the tissues. We never apply an electrical current, constant or faradic, that we do not develop in the tissues a certain amount of ozone, and probably it is through this agent that we often get the effects which are realized by the application of the current.

Dr. TIIEODORE Diller, of Pittsburg-Regarding the lessened resistance in Graves' disease, it seems to me that the explanation offered is a rather reasonable one. The increased moisture of the skin, together with the capillary dilatation would seem to me to be sufficient to account for the phenomenon. This opens up another thought, which is, that this lessened resistance being so constantly present in Graves' disease may be useful as a diagnostic feature. For instance, I have on two occasions seen cases of tachycardia. Very often this increased heart's action is the first symptom of Graves' disease, and I quite agree with Dr. Herdman that it is the most constant symptom. In cases of tachycardia, therefore, it would be well to measure the resistance, and it might lead to important indications. I would like also to record my experience with the constant current in Graves disease. It has been exceptionally unsatisfactory. I have never seen it do much good. Only recently, after a six weeks' course of treatment, the patient coming to my office, there was no good result whatever. The patient was then put upon some medication, and three or four weeks later was sent to a hospital and remained in bed for six weeks without medicine of any kind. Under the rest treatment there was marked improvement. I believe that of all forms of treatment known to me that rest is the most efficacious. I would like to ask these gentlemen who have recorded observations, in what condition the patients were who were receiving galvanism; whether they were in bed or going about.

Dr. Hugh T. Patrick-I am sorry that my personal experience can not contribute to our knowledge of the decrease in resistance to the electrical current. In most of the cases in which it was tested, there was undoubted diminution. The explanations which are thus far produced hold good for some but not for all of the cases. liegarding the conditions of the patients I saw treated, most of them were able to be about, but some of them were in bed. The worst case I saw was that of a woman whom I observed almost constantly during the better part of a year. She was better and worse, better and worse under galvanic treatment, and finally she was decidedly worse. She was then put into a hospital and was there so bad that she could not turn over in bed. She had hallucinations, her chest expansion was about threefourths of an inch and her pulse at times could not be felt at the wrist. We all expected her death. She went home, nowever, and within six weeks after leaving the hospital had gained almost fifty pounds in weight under practically no treatment at all but rest at home, whereas before she had grown worse at home under galvanic treatment.

\section{OBSERVATIONS ON SOME CHARACTERISTICS} AND RELATIONS OF THE DYNAMIC AND STATIC FORMS OF ELECTRICITY. Whead in the Section on Neurology and Medical Jurisprudence at th
Forty-sixth Annual Meeting of the American Medical Association, at Baltimore, Md., MaY 7-10, 1895.

\section{BY A. D. ROCKWELI, M.D.}

NEW YORK.

The more thoroughly one studies electro-therapeutics in all its relations, medical and surgical, the clearer it becomes that the real scientific basis for the use of electricity in medicine and surgery is found in electro-physics more than in electro-physiology; and therefore in studying the therapeutic characteristics of electricity, and the relations of its various forms to each other, we can not be too well grounded in the laws of electro-physics.

One of the most perplexing questione to the tyro in electro-therapeutics relates to the differential indications for its use, but if one is well equipped with a knowledge of physics, with a well directed clinical experience, the various special problems that arise in practice, whether of a theoretical or a practical character, very quickly resolve themselves. Often in discusaing the subject with members of the profession more or less interested in electro-therapeutics, I have noticed a manifest tendency to use one form to the exclusion of the others, and an especial tendency to discard the faradic current, in favor either of the galvanic or static electricity.

The contention is, on the one hand, that its quantity is so small as compared with the current direct from the cells, that to mechanical infiuences alone must be attributed whatever beneficial effects follow its use and, on the other, that its nutritional effects are inferior to the static form of electricity because of the tremendous electro-motive force or voltage of the latter. Broadly speaking, seeing that static electricity is all voltage with little amperage or quantity, and that the galvanic current is all amperage with little vol tage - while the faradic current occupies a position between the two-there are in these conclusions a manifest contradiction. The truth is that each has, in some respects, a special field of its own, and no one of the manifestations of electricity can be dispensed with, if one expects to get all the results that it is capable of giving. In regard to the faradic current therefore, it has been urged that other mechanical methods-massage, tapping, and contrivances for producing rapid vibratory movements are equally serviceable. Those, however, who hold these views have but a very incorrect appreciation of the true action of the faradic current, and have certainly fallen far short of completeness in their practical experience with it.

Many years ago, when I first began to use electricity in practice, my efforts were of necessity confined to the faradic current. Galvanic apparatus was not obtainable, and whenever it was desired to use the galvanic current one had to resort to the inconvenient and ill-smelling voltaic pile. This necessity was not altogether without its advantages, however, since it, for the time being, relieved me of the somewhat perplexing problem of current differentiation and enabled me to give undivided attention to the faradic current. One of the most common observations as to the effects of a thorough general application was a relief of muscular tire after prolonged activity, and an increase in the flexibility of limbs that had become sore and stiff after the rest following excessive and unaccustomed muscular exertion. One does not have to search far for a rational explanation of these well-known effects of electricity, although at the time a general want of appreciation of the physical characteristics of the current gave to most of the explanations offered a fanciful rather than a scientific and practical basis.

Mechanical influences were undoubtedly predominant, not, however, as manifested by vigorous muscular contraction, but through molecular agitation, sufficient to give passive exercise to both the superficial and the deeper lying tissue. In these cases we get, associated with cell exhaustion, a condition of circulatory sluggishness with a deposit of the toxic 